\title{
Knowledge and practices regarding pharmacoeconomics among resident doctors in a tertiary care teaching hospital
}

\author{
Reshma Raj A. R., M. J. Sudha*, S. Viveka
}

\begin{abstract}
${ }^{1}$ Medical Undergraduate Student, Azeezia Institute of Medical Sciences and Research, Kollam, Kerala, India ${ }^{2}$ Department of Pharmacology, Azeezia Institute of Medical Sciences and Research, Kollam, Kerala, India

${ }^{3}$ Department of Anatomy, Azeezia Institute of Medical Sciences and Research, Kollam, Kerala, India
\end{abstract}

Received: 21 April 2020

Revised: 13 May 2020

Accepted: 15 May 2020

\section{*Correspondence:}

Dr. M. J. Sudha,

Email: sudhasudhasudha@gmail.com

Copyright: ( $)$ the author(s), publisher and licensee Medip Academy. This is an open-access article distributed under the terms of the Creative Commons Attribution Non-Commercial License, which permits unrestricted non-commercial use, distribution, and reproduction in any medium, provided the original work is properly cited.

\begin{abstract}
Background: With skyrocketing health care costs, even the essential care provided by the health care service providers need to be evaluated under the lens. The development of nationwide awareness of cost-benefit, cost-utility and cost-effectiveness of services is the need of the hour. The objectives of the present study were to assess the knowledge about pharmacoeconomics among resident doctors and to assess the clinical application of pharmacoeconomics among them.

Methods: A cross sectional questionnaire-based survey was conducted among resident doctors involving both interns and post-graduates of a teaching medical college. There were 20 questions; initial ten were for knowledge assessment and next ten questions assessed practical applications. Questions assessed the knowledge regarding components of pharmacoeconomics, direct and indirect medical costs, and application of pharmacoeconomics, local costeffectiveness decisions and advantages of pharmacoeconomics.

Results: Of the 118 participants who took part in the study, 42 were clinicians working in medical college hospital, 12 were clinicians working in dental college hospital, 24 medial postgraduates, 30 dental postgraduates and 10 interns. Nearly $90 \%$ of the respondents opine that concepts of pharmacoeconomics are not followed in every teaching hospital in India. Many participants (90\%) opined that health economics and pharmacoeconomic are different. Nearly $94 \%$ of participants have not under gone any training regarding pharmacoeconomics. More than $95 \%$ respondents have opined that principles of pharmacoeconomics has to be introduced into current medial undergraduate curriculum. Conclusions: This study shows light on the knowledge and practices of resident doctors regarding principles of pharmacoeconomics. This study has revealed the level of awareness of younger generation regarding pharmacoeconomics.
\end{abstract}

Keywords: Cost-benefit, Cost-effectiveness, Knowledge, Pharmacoeconomics, Practices

\section{INTRODUCTION}

The description and analysis of costs of drug therapy to health care systems and society is pharmacoeconomics. ${ }^{1}$ As overall expenditure in health care system is raising, the stakeholders are sensitive to direct and indirect costs involved. As with any system, prime question lingering in minds of everyone is does the costs involved in health care is efficient? To address this issue, pharmacoeconomics is evolving as a sub-specialty.,

As an economic discipline, pharmacoeconomics evaluates the use of pharmaceutical products and health services including national programs by individuals, 
hospitals and firms. As pharmacology discipline, pharmacoeconomics evaluates the efficiency and benefits of these services among individuals. ${ }^{4}$ It considers various 'inputs' of healthcare sector starting from economics of drug development and marketing to direct use of individual modes of treatment and costs involved in therapy from first point of patient contact. It considers all aspects of 'outcomes' from efficiency of care given to patients, quality of life after contact with health care, benefits and utility of health care services. ${ }^{5}$ Many theories of economics also apply here. The sole purpose of pharmacoeconomics is to examine the worthiness of service that influences the decision making while treating. ${ }^{6}$ Such analysis will have impact in policy makers to advice modalities of treatment to larger masses.

Pharmacoeconomics studies compare costs, clinical, and humanistic outcomes associated with different therapies. The evaluation mechanisms delineated are often helpful in demonstrating the cost impact of innovative treatments, granting greater acceptance by healthcare providers, administrators, and the public. Pharmacoeconomics mainly has four components: costbenefit analysis, cost-effectiveness analysis, cost-utility analysis and cost-minimization analysis. ${ }^{1}$

With skyrocketing health care costs, even the essential care provided by the health care service providers need to be evaluated under the lens. The development of nationwide awareness of cost-benefit, cost-utility and costeffectiveness of services is the need of the hour. ${ }^{7}$ Despite the rapid growth in clinical research, in India, large masses of health care service providers are not fully aware of principles of pharmacoeconomics. This study will show light on this issue. International Society of Pharmacoeconomics and Outcomes Research (ISPOR) has formed an Indian chapter and is working to establish the pharmacoeconomic grounds of health care services. ${ }^{8}$

With this background, this study was designed to evaluate the knowledge about pharmacoeconomics among resident doctors and to assess the clinical application of pharmacoeconomics among them.

\section{METHODS}

A cross sectional questionnaire-based survey was conducted among resident doctors involving both interns and post-graduates of a teaching medical college. After institutional ethics committee approval and informed consent procedure, a self-administered questionnaire was given to all participants who are willing to take part in the survey. Questionnaire was pilot tested among faculty of department of pharmacology. Necessary changes were done in the questionnaire according the suggestions of faculty members.

\section{Questionnaire components}

The first part of questionnaire addressed knowledge and second part addressed practices among resident doctors regarding the pharmacoeconomics. Questions assessed the knowledge regarding components of pharmacoeconomics, direct and indirect medical costs, and application of pharmacoeconomics, local costeffectiveness decisions and advantages of pharmacoeconomics. Questions also assessed the knowledge regarding proper implementation of principles of pharmacoeconomics; most commonly used pharmacoeconomic analysis, quality of life years measurement, goal of expression of benefits associated with health care services, differential perspectives of pharmacoeconomics, comparison of costs involved in different procedures and application of principles of pharmacoeconomics in India. Questions were of multiple-choice type with single best answer, open ended questions and yes/no type of answers. There were 20 questions; initial ten were for knowledge assessment and next ten questions assessed practical applications. All questions in the survey questionnaire were assigned one mark for correct response and zero for incorrect responses.

Several questions were adopted from similar studies in the past with considerable changes. ${ }^{9-11}$ The questionnaire components were tested by two subject experts in the department of pharmacology, other than the guide of the study. Later, the questionnaire was pilot tested among total five senior residents belonging to department of dermatology and general medicine. The doctors' pilot testing the questionnaire were not included in the final list of participants for the study. A Cronbach's alpha score of more than 0.8 indicated an internal consistency during validation.

\section{Statistical analysis}

The data was tabulated and analysed using MS Excel. All continuous data were expressed as mean with standard deviation. Questionnaire parameters are expressed both in numbers and percentages.

\section{RESULTS}

A total of 124 participants returned the questionnaire back. Of which, 118 responses were analyzed and rest were rejected as they were incomplete. Of the 118 participants, 42 were clinicians working in medical college hospital, 12 were clinicians working in dental college hospital, 24 medial postgraduates, 30 dental postgraduates and 10 interns.

All answers for knowledge assessment part of questionnaire are tabulated in Table 1 . More than $70 \%$ of the respondents were aware of term pharmacoeconomics, though majority accept that the they do not discuss the concepts during clinical posting or regular classes. Nearly $90 \%$ of the respondents opine that concepts of pharmacoeconomics are not followed in every teaching hospital in India. Many participants (90\%) opined that health economics and pharmacoeconomics are different. 
Nearly $94 \%$ of participants have not under gone any training regarding pharmacoeconomics. More than half the participants have not answered $3 / 4^{\text {th }}$ of knowledgebased questions about pharmacoeconomics correctly.

Table 1: Responses of participants regarding knowledge about pharmacoeconomics $(\mathbf{n}=118)$.

\begin{tabular}{|lll|}
\hline Knowledge based assessment regarding pharmacoeconomics & $\mathbf{N}(\%)$ & N $(\%)$ \\
\hline Are you aware of the term pharmacoeconomics? & Yes & No \\
\hline Have this term discussed during regular classes? & $83(70.3)$ & $29(29.7)$ \\
\hline Have this term discussed in clinical posting? & $8(6.8)$ & $110(93.2)$ \\
\hline $\begin{array}{l}\text { Do you think every teaching hospital in India are following pharmacoeconomics } \\
\text { guidelines? }\end{array}$ & $17(14.4)$ & $101(85.6)$ \\
\hline Is Health economics and Pharmacoeconomics are same? & $12(10.2)$ & $106(89.8)$ \\
\hline Have you gone under any training/ workshop on pharmacoecoconomics? & $7(10.2)$ & $106(89.8)$ \\
\hline Single best response MCQs & Correct answer & Wrong answer \\
\hline Pharmacoeconomics components-negating & $60(50.8)$ & $58(49.2)$ \\
\hline $\begin{array}{l}\text { Direct medical cost and an indirect nonmedical cost-medical professional time } \\
\text { and lost productivity }\end{array}$ & $21(17.8)$ & $97(82.2)$ \\
\hline $\begin{array}{l}\text { Pharmacoeconomics should be the only consideration when making a drug } \\
\text { therapy decision-false }\end{array}$ & $79(66.9)$ & $39(33.1)$ \\
\hline Local pharmacoeconomics evaluation is expensive and time-consuming & $10(8.5)$ & $108(91.5)$ \\
\hline
\end{tabular}

Table 2: Tabulation of responses of participants regarding practical use of principles of pharmacoeconomics, $(\mathrm{n}=118)$.

\begin{tabular}{|c|c|c|}
\hline & $\mathbf{N}(\%)$ & $\mathbf{N}(\%)$ \\
\hline Practice based assessment regarding pharmacoeconomics & Yes & No \\
\hline Are you applying pharmacoeconomics in your clinical practice? & 87 (73.7) & $31(26.3)$ \\
\hline Most commonly used pharmacoeconomics analysis is & $68(57.6)$ & $50(42.4)$ \\
\hline Single best response MCQs & Correct answer & Wrong answer \\
\hline Cost benefit analysis - measures outcome in monetary units & $63(53.4)$ & $55(46.6)$ \\
\hline Quality adjusted life years measured in analysis & $49(41.5)$ & $69(58.5)$ \\
\hline In clinical pharmacy service, cost-benefit analysis is expressed in rupee value & $64(54.2)$ & $54(45.8)$ \\
\hline $\begin{array}{l}\text { Costs and consequences should be identified and measured relative to the } \\
\text { perspective(s) selected - true }\end{array}$ & $33(28)$ & $85(72)$ \\
\hline $\begin{array}{l}\text { National highway project and vaccination programme comparison - cost benefit } \\
\text { analysis }\end{array}$ & 27 (22.9) & $91(77.1)$ \\
\hline Inclusion of pharmacoeconomics in medical under graduate curriculum & $113(95.8)$ & $5(4.2)$ \\
\hline \multicolumn{3}{|c|}{$\begin{array}{l}\text { Which phase of medical undergraduate education it has to be introduced? } 2^{\text {nd }} \text { phase }-99(87.6 \%), 3^{\text {rd }} \text { phase }-9(8 \%) \text { and } \\
4^{\text {th }} \text { phase }-5(4.4 \%)\end{array}$} \\
\hline Pharmacoeconomics improve current health system performance & $117(99.2)$ & $1(0.8)$ \\
\hline
\end{tabular}

Responses for practice-based assessment part of questionnaire is tabulated in Table 2. Nearly $74 \%$ respondents opined that they are applying concepts of pharmacoeconomics in clinical practice. 68 participants have given the correct response of cost - effectiveness analysis as most commonly used pharmacoeconomic analysis. Among answers for single best response in MCQs assessing practice of pharmacoeconomics, the correct responses for most questions are hovering around $50 \%$ mark. More than $95 \%$ respondents have opined that principles of pharmacoeconomics has to be introduced into current medial undergraduate curriculum. $87 \%$ opined that it has to be introduced in $2^{\text {nd }}$ phase of medial under graduate training. Almost all opined that application of pharmacoeconomics improve health system performance in India.

\section{DISCUSSION}

Pharmacoeconomics as a subsidiary discipline is being established in many parts of the world. It has made a niche as independent department in few universities in Iran and many other countries. Many research institutes have set up separate wing of pharmacoeconomics. ${ }^{8,12,13}$ International society for pharmacoeconomics and outcome research (ISPOR) through its India regional chapter has drafted the first proposed pharmacoeconomics guidelines for India. ${ }^{8}$ Authors are at a crucial time wherein pharmacoeconomics and outcome research principles are guiding health care system. It is the need of the hour that all stakeholders are aware of principles and process of pharmacoeconomics and apply the same in every day practice. ${ }^{14}$ 
There has been heightened interest in different components of pharmacoeconomics recently. ${ }^{15}$ With recent improvement in citizen participation in governance, administrations are in position to expect higher scrutinization in all fronts and health sector is not isolated. Any modifications in health policy has to prove its mettle in pharmacoeconomic front. Therefore, academicians are stressing on concepts of pharmacoeconomics more than ever before.

There are few studies done in Indian medical fraternity evaluating knowledge and practices regarding pharmacoeconomics. Tahashildar $\mathrm{J}$ has reported that there was no academic exposure to concepts of pharmaco-economics. ${ }^{9}$ Health care professionals in administrative posts had not any opportunity to get themselves trained in principles of pharmacoeconomics. Reports states that less than $20 \%$ of health professionals have heard about pharmacoeconomics.9-11 All the studies evaluating the knowledge and practices of pharmacoeconomics affirms that these concepts have to incorporated into the medical undergraduate curriculum and also should be revisited during internship..$^{9,11,16}$ In the studies conducted recently, there is extreme poor response rate to pharmacoeconomic questionnaire based study..$^{10,11}$

In this context, this study, evaluating knowledge and practices of health professionals regarding pharmacoeconomics finds its significance. In this study, authors found that although, many doctors aware of the principles of pharmacoeconomics, there is a felt need to employ these concepts into practices.

\section{CONCLUSION}

This study shows light on the knowledge and practices of resident doctors regarding principles of pharmacoeconomics. This study has revealed the level of awareness of younger generation regarding pharmaco-economics. Such studies may influence the policy makers and academicians to include the principles of pharmacoeconomics in medical undergraduate curriculum.

\section{ACKNOWLEDGEMENTS}

Authors would like to thank all the participants who have undertaken this survey. Authors also thank management and principal of Azeezia Institute of Medical Sciences and Research, Kollam, Kerala, India for allowing us to conduct the survey.

Funding: For this study, the medical undergraduate student has received scholarship under ICMR STS 2018 program

Conflict of interest: None declared

Ethical approval: The study was approved by the Institutional Ethics Committee

\section{REFERENCES}

1. Ahmad A, Patel I, Parimilakrishnan S, Mohanta GP, Chung H, Chang J. The role of pharmacoeconomics in current Indian healthcare system. J Res Pharm Pract. 2013;2(1):3-9.

2. Suh K, Gabriel S, Adams MA, Arcona S. Health economics and outcomes research fellowship practices reviewed. Res Soc Adm Pharm. 2015;11(2):280-7.

3. Potočnjak I, Terešak SD, Radulović B, Trbušić M, Degoricija V. Pharmacoeconomical and added value of acute heart failure studies. InPharmaca: Fifth Adriatic and Fourth Croatian Congress of Pharmacoeconomics and Outcome Research 2015. Available at: http://bib.irb.hr/prikazi-rad?lang=en $\&$ rad=759839. Accessed on $12^{\text {th }}$ March 2020.

4. Danzon PM, Nicholson S. The Oxford handbook of the economics of the biopharmaceutical industry. Oxford University Press; 2012: 618.

5. Samsa GP, Matchar DB, Harnett J, Wilson J. A costminimization analysis comparing azithromycin-based and levofloxacin-based protocols for the treatment of patients hospitalized with community-acquired pneumonia: results from the CAP-IN trial. Chest. 2005;128(5):3246-54.

6. Rogowski W, Payne K, Schnell-Inderst P, Manca A, Rochau U, Jahn B, et al. Concepts of 'personalization' in personalized medicine: implications for economic evaluation. Pharmaco Economics. 2015;33(1):49-59.

7. Berger ML. Health care cost, quality, and outcomes: ISPOR book of terms. Int Society Pharmaco Outcomes Res; 2003:264.

8. International Society of Pharmacoeconomics and Outcomes Research (ISPOR). Available at: http://www.ispor.org/. Accessed on 12 $2^{\text {th }}$ March 2020.

9. Tahashildar J, Kota K, Kumar SK, Tahashildar J, Mohanty L, Ahmed SY. Assessment of the knowledge and perceptions about pharmacoeconomics among medical postgraduate students and healthcare professionals at a tertiary care teaching hospital, Udaipur, India. Int J Curr Res Aca Rev. 2015;3(2):135-42.

10. Savkar MK, Bhat NP, Deepikar G. Shwetha. Evaluation of pharmacoeconomics awareness among post graduates: a questionnaire-based study. Indian J Basic Appl Med Res. 2014;3(3):135-41.

11. Jayasree D, Uppu B, Devi B. A study on awareness of pharmacoeconomics among post graduates in a tertiary care teaching hospital. Int J Res Med Sci. 2016;3:1597-603.

12. Center for Pharmacoepidemiology and Pharmacoeconomic Research, College of Pharmacy, University of Illinois at Chicago, 2016. Available at: https://pharmacy.uic.edu/research/pharmacoepidemio logy-pharmacoeconomic. Accessed on $12^{\text {th }}$ March 2020.

13. Pharmacoeconomics, Department of Pharmaceutical Outcomes and Policy, College of Pharmacy 
University of Florida. Available at: http://pop. pharmacy.ufl.edu/research/areas-of-research/pharmacoeconomics/. Accessed on $12^{\text {th }}$ March 2020.

14. Alefan Q, AlImam S, Mukattash T, Mhaidat N, Alabbadi I, Rascati K. Pharmacoeconomics education in WHO Eastern Mediterranean region. Curr Pharm Teach Learn. 2015;7(6):819-25.

15. Rascati KL, Drummond MF, Annemans L, Davey PG. Education in pharmacoeconomics. Pharmaco Economics. 2004;22(3):139-47.
16. Law AV, Jackevicius CA, Bounthavong M. A monograph assignment as an integrative application of evidence-based medicine and pharmacoeconomic principles. Am J Pharm Educ. 2011;75(1):1.

Cite this article as: Reshma RAR, Sudha MJ, Viveka S. Knowledge and practices regarding pharmacoeconomics among resident doctors in a tertiary care teaching hospital. Int J Basic Clin Pharmacol 2020;9:1114-8. 